Original Research Paper

\title{
An Experimental Comparison for Compression of PLA Specimens Printed in In-Plane and Out-of-Plane Directions
}

\author{
Salvatore Brischetto and Roberto Torre \\ Department of Mechanical and Aerospace Engineering, Politecnico di Torino, Torino, Italy
}

\author{
Article history \\ Received: 31-07-2020 \\ Revised: 21-09-2020 \\ Accepted: 24-09-2020 \\ Corresponding Author \\ Salvatore Brischetto \\ Department of Mechanical and \\ Aerospace Engineering, \\ Politecnico di Torino, Torino, \\ Italy \\ Email: salvatore.brischetto@polito.it
}

\begin{abstract}
The present work proposes an experimental comparison between the in-plane and out-of-plane compressive behaviors of 3D printed PolyLactic Acid (PLA) specimens. These specimens are produced via the Fused Deposition Modeling (FDM) technique by using two different printing directions: the first printing direction in the $x z$ plane allows experimental compression tests in the out-of-plane direction; the second printing direction in the $x y$ plane allows experimental compression tests in the in-plane direction. The specimens are more rigid in the out-of-plane direction than in the in-plane direction. In the first case, a bigger linear compressive Young modulus has been found and both maximum stress and proportional limit stress were determined. In the second case, the linear compressive Young modulus is smaller and the specimens are less rigid but at the same time more resistant: in fact, no maximum stress and proportional limit stress have been obtained because the test machine has reached the maximum applicable load. This research demonstrates as the compressive behavior of 3D FDM printed polymeric elements depends on the printing and test directions and this feature is fundamental when such elements will be used for structural applications. The experimental tests performed in the present paper are accompanied by statistical and capability analyses for the dimensional parameters and for the mechanical properties in order to also evaluate the stability of the production process and the validity ranges for the mechanical characteristics.
\end{abstract}

Keywords: 3D Printing, Fused Deposition Modeling, Polymeric Specimens, Compression Tests, In-Plane Behavior, Out-of-Plane Behavior

\section{Introduction}

Fused Deposition Modelling (FDM) is a rapidly growing additive manufacturing technology because of its ability to produce functional elements with complex geometries (Chacón et al., 2017). It is becoming very exciting for the academic and industrial researchers (Mohamed et al., 2017) even if great attention must be devoted to the strength loss in 3D printed elements with respect to elements produced via traditional manufacturing methods (Raney et al., 2017). The booming interest in Additive Manufacturing (AM) is seeing a rising number of industries and research entities adopting this technology into their manufacturing practices (Keshavamurthy et al., 2021). Due to the production process, the mechanical properties of a 3D-printed element are substantially different from those of the same element, made of the same material, but obtained via a different manufacturing technique (Dal Maso and Cosmi, 2018).
Moreover, the filaments exhibited better tensile performance with respect to their corresponding printed samples (Oviedo et al., 2020). In recent years, the present authors conducted several researches (Ferro et al., 2016; Brischetto et al., 2017a) in order to use polymeric materials and the FDM technique to produce structural elements for small UAVs subjected to limited loads; an example is the multipurpose modular drone known as PoliDrone (Brischetto et al., 2016) and patented in (Brischetto et al., 2018a). The Selective Laser Melting (SLM) technology, already applied by the first author in the past for the production of multifunctional metallic panels for de-icing and anti-icing systems in aircraft (Ferro et al., 2017; Bici et al., 2018), cannot be used in the case of small UAVs because of weight and cost reasons and also because this technology cannot be combined with polymeric materials. For these reasons, recently, the authors deepened the study on the use of polymeric materials (in particular, Acrylonitrile 
Butadiene Styrene (ABS) and PLA) for 3D FDM printing of small structural elements. Therefore, in (Brischetto et al., 2019) the mechanical properties of polymeric specimens produced via FDM technology were investigated also considering the printing parameter effects. A capability and statistical analysis was conducted for both the mechanical and geometrical characteristics. The authors suggested in (Torre et al., 2018) a possible characterization procedure for PLA specimens produced via FDM printing process by using an analogy with composites embedding unidirectional long fibres. In Brischetto et al. (2018b), the present authors also investigated the possibility of producing sandwich elements made of PLA and ABS in order to reduce the weight in some structural applications, several bending tests were performed in these cases. From the studies just mentioned, the need arises to investigate the effects of the different printing directions on the mechanical properties of 3D FDM printed polymeric elements. In order to analyze these features, in the present paper the effects of the printing direction on the compressive behavior of 3D FDM printed PLA elements have been investigated by means of appropriate capability and statistical analyses after opportune experimental tests. The knowledge of these effects is fundamental when such polymeric elements produced by 3D FDM technique will be used for structural purposes. Further details on the importance of the study of the effects of printing parameters on the mechanical properties of 3D printed elements can be found in (Brischetto et al., 2018c; 2017b).

In order to better remark the innovative aspects of the proposed paper, a brief literature survey about the material and printing parameter effects on the 3D FDM production of polymeric elements is proposed below. Gebisa and Lemu (2019) investigated the effect of process parameters on the tensile properties of ULTEM 9085 polymeric material printed by means of the FDM technique. Among the considered parameters, only the raster angle significantly influenced the tensile properties of the material. The comprehensive analysis reported in (Abeykoon et al., 2020) was based on different techniques (such as tensile, bending and compression tests, Differential Scanning Calorimetry (DSC), Thermal Gravimetric Analysis (TGA), Thermal Imaging and Scanning Electron Microscopy (SEM)) in order to evaluate the effects of infill pattern, infill density, infill speed and printing materials on the properties of 3D FDM printed specimens. In Yadav et al. (2020), the effects of the infill pattern and build orientation were investigated for ABS elements for automotive applications produced via the FDM technique. In order to better remark the effects of the materials and infills, Abbot et al. (2019) and Vidakis et al. (2017) proposed a comparison between experimental tests and finite element analyses performed using the same loads.
Martínez et al. (2013) instead proposed only numerical simulations for such structure and material types. The same question was also investigated from an analytical point of view in (Croccolo et al., 2013) where an analytical model was developed to predict the strength and the stiffness properties as functions of both the number of contours deposited around the component edge and the setting of the other main parameters in the deposition process. Salim et al. (2019) investigated the mechanical properties of PLA and ABS to see the material effects: the experimental results showed that the PLA had better tensile performance in terms of strength, strain and modulus of elasticity. In the case of flexural test, PLA showed better performance in terms of strength and modulus of elasticity but ABS was more superior in terms of strain. Another important feature is the influence of the deposition layer thickness on the mechanical properties of polymeric FDM printed specimens as discussed in (Nomani et al., 2020) for the ABS. In the case of ABS, severe compression conditions were attempted in (Guessasma et al., 2016) in order to remark the anisotropy due to different building orientations. Building orientations significantly impacted the mechanical properties for ABS and fiber reinforced polymers (Türk et al., 2017). In Sood et al. (2012), an extensive study was conducted to understand the effects of five different parameters such as layer thickness, part build orientation, raster angle, raster width and air gap on the compressive behavior of $3 \mathrm{D}$ printed polymeric specimens. In Corapi et al. (2019), the orthotropy of the FDM printed PLA elements was remarked by means of uniaxial tensile tests performed for the determination of mechanical strength, modulus of elasticity and percentage elongation when the spatial growth directions $x, y$ and $z$ changed. Mishra et al. (2017) experimentally investigated the effects of layer thickness, part orientation, air gap, raster width, contour number and raster angle on the compressive strength of the FDM produced polymeric elements. Similar process parameters were considered in (Lee et al., 2007) where raster orientation, air gap, bead width, color and model temperature were investigated for FDM processes. The material consumption and compressive strength in FDM printed polymeric objects were investigated in (Dev and Srivastava, 2020) as functions of layer thickness, build orientation and infill patterns. Uniaxial tensile tests and dynamic mechanical analysis for 3D FDM printed polymeric elements were conducted in (Wang et al., 2020) to investigate several effects on the printing process such as those due to temperature variations, printing angle, layer thickness, fill rate and nozzle temperature. Wang et al. (2017) remarked that PLA is one of the most popular thermoplastics for fused deposition modeling. However, due to its semicrystalline nature, the relation between printing 
parameters and properties is more complicated than amorphous thermoplastics such as the ABS. PEEK (PolyEther-Ether-Ketone) is a typical semicrystalline thermoplastic widely used in the FDM technology; in order to fabricate the PEEK samples for tensile tests, the investigation of the relationship between various thermal processing conditions (the raster angle, nozzle temperature and ambient temperature) and its mechanical properties is fundamental (Zhao et al., 2020). Zhang and Wang (2020) observed an interesting filling density effect in the FDM printed polymeric elements: the interfacial bonding strength firstly increased until to an optimal value and then decreased as the filling density increased. Another interesting effect was the positioning of the sample in the test machine: in the experimental results by (Kozior and Kundera, 2017), the influence of location and direction of the models in the virtual platform on their selected mechanical properties (such as Young modulus and stress relaxation) during uniaxial compression tests was discussed. Manufacturing parameters such as wall thickness, orientation of building wall lines and orientation of infill pattern were studied in (Lluch-Cerezo et al., 2019) for FDM printed PLA elements. Wittbrodt and Peare (2015) investigated tensile strengths of FDM printed PLA elements in various colors. Five colors (white, black, blue, gray and natural) of commercially available filaments of PLA were tested to better understand such an effect. Another important effect in polymeric FDM printed elements was that due to the production of appropriate supports; in (Galantucci et al., 2008), topologically optimized parts were created with internal geometry, using a narrowwaisted structure that avoided the necessity of building supports. In order to characterise and study the behaviour of the obtained low density parts, an experimental plan was designed and executed. A parametric study was presented in (Garzon-Hernandez et al., 2020) in order to understand the effects of different manufacturing parameters on the mechanical performance of FDM printed ABS specimens. In Yao et al. (2020), experimental measures and theoretical analyses were compared to investigate the effect of printing and separation angles on the 3D FDM production of PLA elements. Other effects to be considered were the finish of the FDM printed element and its porosity; as suggested in (Mirón et al., 2017), the good finish of the piece could have positive effects on the mechanical properties. In Justo et al. (2018), the high porosity in 3D printed long fibre reinforced composites showed a decreasing of obtained mechanical properties. A wide range of virgin thermoplastic polymers and Polymer Matrix Composites (PMCs) an be used as raw materials in FDM printing (Singh et al., 2020). The effects of the reinforcements were also remarked in (Ferreira et al., 2017) where PLA was reinforced with short carbon fibers. ABS and PLA were the most commonly used filaments in 3D FDM printing for the study conducted in (Dhinesh et al., 2020): blends of PLA and ABS were produced in various compositions (20\% ABS and $80 \%$ PLA; $50 \%$ ABS and $50 \%$ PLA; $80 \%$ ABS and 20\% PLA) and they were tested for their resistance against tensile and flexural loads. Lanzotti et al. (2019) compared virgin and recycled PLA in terms of mechanical properties and they concluded that $3 \mathrm{D}$ printing with recycled PLA may be a viable option. In the mechanical investigations for polymeric FDM printed elements, the fatigue tests are less numerous, some examples were proposed in (Ezeh and Susmel, 2018; Gomez-Gras et al., 2018) where the fatigue life was connected also with several printing parameters.

In works from literature and discussed in the previous part, it is clear how an extensive compressive investigation could very useful to better understand the mechanical properties of the FDM printed polymeric elements and their relation with the printing directions. For these reasons, the present work proposes an experimental investigation where compressive tests are conducted on PLA elements 3D printed in in-plane and out-of-plane directions. Capability and statistical analyses are proposed for geometric parameters and for mechanical properties. In the first case, it is possible to evaluate the printing process in two different directions. In the second case, the mechanical properties in the two printing directions are also given with opportune limits of acceptance. The section 2 is devoted to the description of the specimen production, section 3 discusses the experimental tests and the mechanical property collections. Section 4 proposes the statistical and capability analysis for both geometrical and mechanical properties; the most important results and developments are also discussed. The main conclusions are given in section 5 .

\section{Production of Specimens}

Both specimen types have been drawn and then produced in accordance with the standard reference ASTM D695 (Standard, 2015). The ASTM D695 employed for classical polymers has here been modified to be used for FDM 3D printed polymers. Therefore, parallelepiped-shaped specimens with a square cross section have been produced using two different printing planes which are the $x y$ and the $x z$ one for in-plane tests and out-of-plane tests, respectively. 10 specimens have been printed for in-plane tests and other 10 specimens have been printed for out-of-plane tests. Each time, the 10 specimens have been printed in two different periods giving two families composed by 5 specimens per each one. The raster angle orientation sequence is always equal to $\pm 45^{\circ}$ in order to have a criss-cross sequence with rectilinear infill. This feature should allow an 
isotropic behavior. The first layer height equals $0.2 \mathrm{~mm}$, the height of the further layers equals $0.1 \mathrm{~mm}$. In the case of in-plane compression tests, no perimeter beads have been used because of the simplicity of the geometry and in particular to avoid unwanted reinforcement phenomena in the compression direction. For out-ofplane compression tests, the specimens have 1 perimeter bead to facilitate the printing in the long dimension direction. The infill speed is $30 \mathrm{~mm} / \mathrm{s}$. The extruder temperature for the first layer is $215^{\circ} \mathrm{C}$, it becomes $210^{\circ} \mathrm{C}$ for the other layers. The bed temperature for the first layer and the subsequent printed layers is imposed equal to $30^{\circ} \mathrm{C}$. All these data are valid for both specimen types and they have been already successfully applied in (Brischetto and Torre, 2020) for several specimen types for compression and tensile tests.

\section{Specimens Printed in Out-of-Plane Direction}

Specimens for out-of-plane compression tests have been printed in the $x z$ plane as indicated in Fig. 1. As shown in Fig. 2 and in Table 1, the target value for the two dimensions of the square cross section in the $\mathrm{X}$ and $\mathrm{Y}$ directions is $12.70 \mathrm{~mm}$; the target value for the length of the specimens in the $\mathrm{Z}$ direction is $40 \mathrm{~mm}$. The target weight $\mathrm{W}$ in gramms given in Table 1 has been calculated as the product between the three target geometrical dimensions (this is the target volume), the mass density of the PLA filament (1.25 $\mathrm{g} / \mathrm{cm}^{3}$ ) and 1 (because the imposed infill density equals 1). Therefore, the target weight $\mathrm{W}$ is $8.06 \mathrm{~g}$. The actual dimensions in the three directions $X, Y$ and $\mathrm{Z}$ have been measured for each specimen by means of a digital caliper. The actual weight $\mathrm{W}$ for each specimen has been determined by using a digital weight scale. All the actual geometrical dimensions and weights are summarized in Table 1 where they are grouped in families 1 and 2 .

\section{Specimens Printed in In-Plane Direction}

Specimens for in-plane compression tests have been printed in the $x y$ plane as indicated in Fig. 3. As shown in Fig. 2 and in Table 2, the target value for the two dimensions of the square cross section in the $\mathrm{Y}$ and $\mathrm{Z}$ directions is $12.70 \mathrm{~mm}$; the target value for the length of the specimens in the $\mathrm{X}$ direction is $40 \mathrm{~mm}$. The target weight $\mathrm{W}$ in Table 2 is $8.06 \mathrm{~g}$ and it has been calculated in the same way already described for specimens printed in out-of-plane direction. The actual dimensions in the three directions $\mathrm{X}, \mathrm{Y}$ and $\mathrm{Z}$ and the actual weight $\mathrm{W}$ have been determined with the same procedures already seen for the specimens printed in out-of-plane direction. All these values for the 10 specimens are shown in Table 2 where the two families (comprising 5 specimens per each one) are clearly indicated.

\section{Experimental Tests and Mechanical Properties}

Both the test types have been conducted in accordance with the standard reference ASTM D695 (Standard, 2015). The employed test machine had two flat plates where the bottom plate remains stationary while the top one moved downward at constant speed. One of the suggested geometry for the tested specimens is that with a square cross section in order to have parallelepiped-shaped specimens. A standardized compression test method for FDM 3D printed polymers has not been developed yet; therefore, the ASTM D695 (Standard, 2015) for classical polymers has been here employed by using several arrangements (see also the details in (Brischetto and Torre, 2020)). A constant speed for the downward movement of the upper crossbar is requested, this speed is here set as equal to $-1.8 \mathrm{~mm} / \mathrm{min}$ (the reference standard usually suggests $-1.3 \pm 0.3$ $\mathrm{mm} / \mathrm{min}$, the actual speed value employed in the present tests is bigger in order to correct some problems for data acquisition in the machine used in the department laboratory). The frequency of data acquisition is equal to $20 \mathrm{~Hz}$, the acquired data are the applied load $P$ in Newton and the displacement $\Delta L$ of the upper crossbar in millimeters. Using these data, the stresses $\sigma$ in $\mathrm{MPa}$ and the no-dimensional strains $\epsilon$ will be obtained as:

$\sigma=\frac{p}{w t}, \quad \epsilon=\frac{\Delta L}{L_{0}}$

where the meaning of $w, t$ and $L_{0}$ in millimeters will be detailed in the next two subsections (all these data are the actual values of each specimen).

The standard reference (Standard, 2015) suggests a slenderness ratio having values between 11:1 and 16:1 in order to avoid buckling phenomena during the compression tests. The slenderness ratio is defined as the ratio between the free length of inflection (or effective length) of the specimen and the least radius of gyration of the related cross section. The specimens here printed and tested have a slenderness ratio value roughly equal to $11: 1$. This ratio comes from the effective length equals $40 \mathrm{~mm}$ (because the two plane plates in the test machine can be considered as two simply supported boundary conditions) and the least radius of gyration of a square cross section that can be calculated as $0.289 \mathrm{w}$.

\section{Out-of-Plane Compression Tests}

The experimental out-of-plane compression tests have been conducted on the 10 specimens described in Fig. 1 and 2 and with the geometrical data given in Table 1. The experimental test has been already described above and it is also valid for the experimental in-plane compression tests. In order to obtain the stresses $\sigma$ in $M P a$ and the no- 
dimensional strains $\epsilon$ as defined in Equation (1), $w$ and $t$ are the actual dimensions of the square cross section in $X$ and $Y$ directions, respectively; $L_{0}$ is the actual length of the specimens measured in the $Z$ direction.

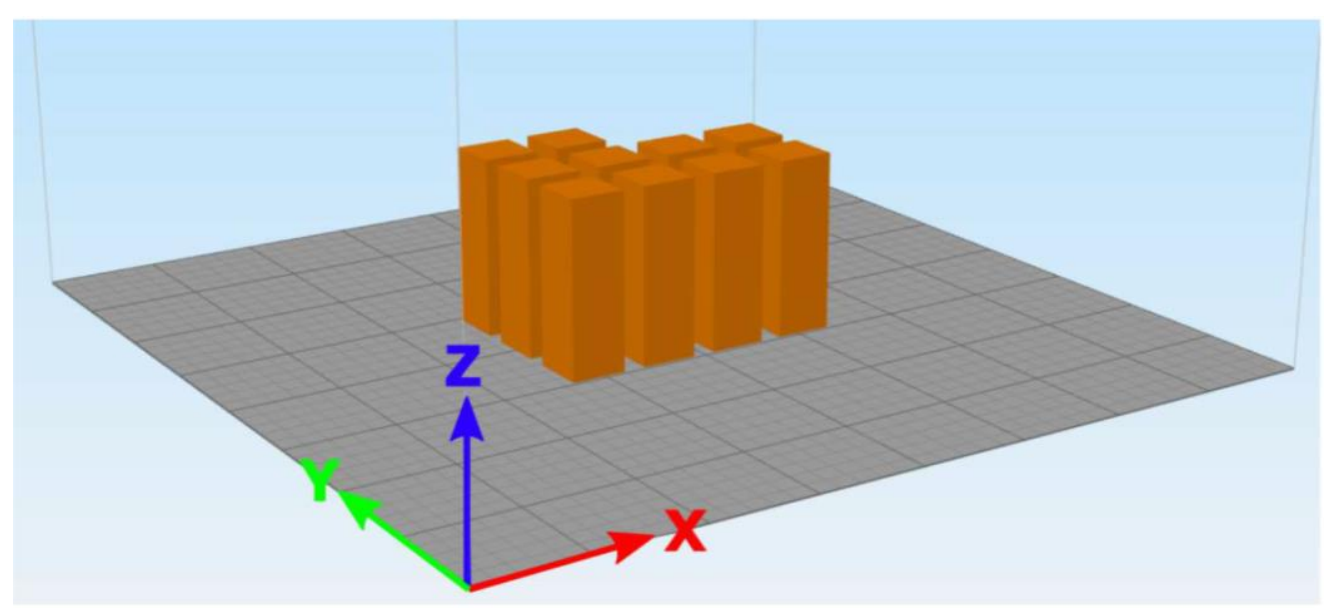

Fig. 1: FDM printing of the specimens in the $x z$ plane for out-of-plane compression tests
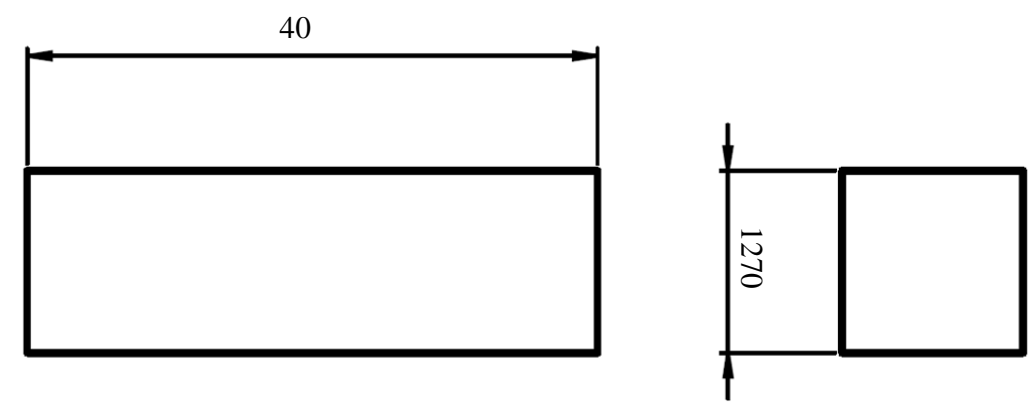

Fig. 2: Geometrical data (in millimeters) of the parallelepiped-shaped specimens printed in out-of-plane and in in-plane directions for compression tests

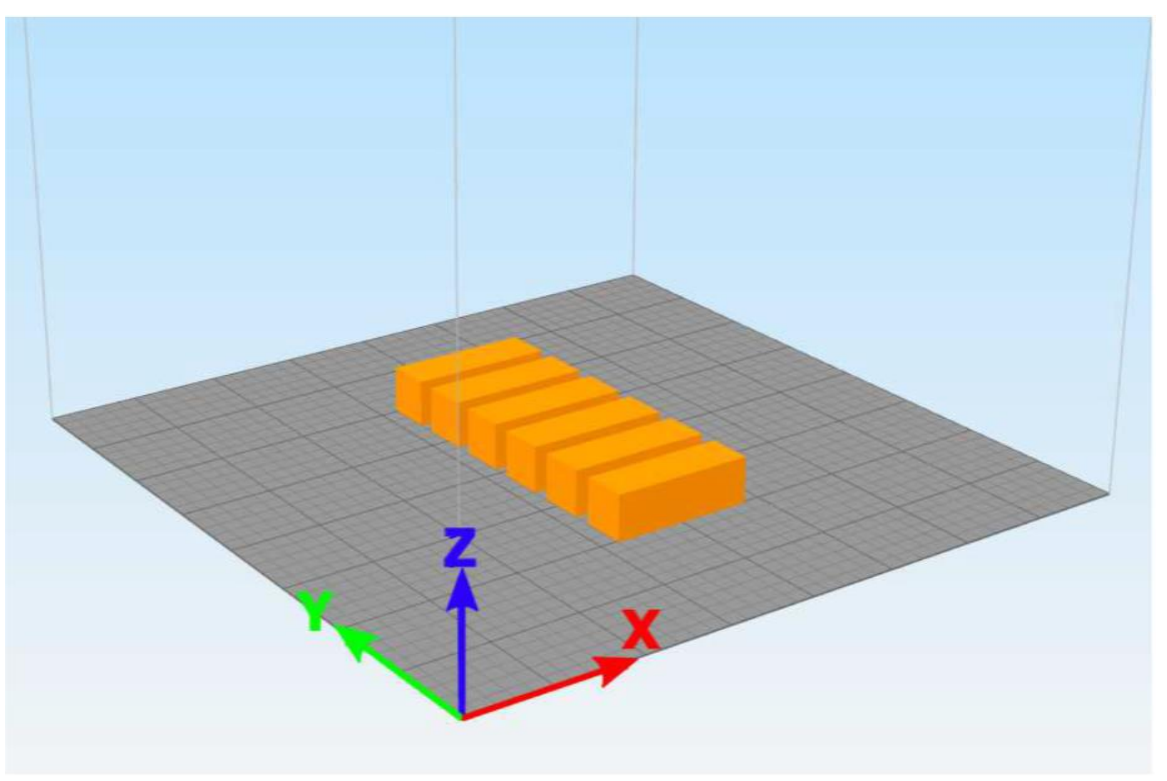

Fig. 3: FDM printing of the specimens in the xy plane for in-plane compression tests 
Table 1: Measured geometrical data and weights for the 10 specimens (divided in two families) produced in the xz plane for out-ofplane compression tests

\begin{tabular}{lllll}
\hline Specimen (family) & $\mathrm{X}[\mathrm{mm}]$ & $\mathrm{Y}[\mathrm{mm}]$ & $\mathrm{Z}[\mathrm{mm}]$ & $\mathrm{W}[\mathrm{g}]$ \\
\hline $1(1)$ & 12.84 & 12.65 & 39.98 & 7.85 \\
$2(1)$ & 12.85 & 12.80 & 39.86 & 7.94 \\
$3(1)$ & 12.84 & 12.66 & 39.84 & 7.90 \\
$4(1)$ & 12.68 & 12.61 & 39.79 & 7.80 \\
$5(1)$ & 12.79 & 12.66 & 39.91 & 7.92 \\
$6(2)$ & 12.76 & 12.63 & 39.83 & 7.92 \\
$7(2)$ & 12.83 & 12.72 & 39.87 & 7.87 \\
$8(2)$ & 12.88 & 12.69 & 39.81 & 7.91 \\
$9(2)$ & 12.85 & 12.84 & 39.77 & 7.97 \\
$10(2)$ & 12.67 & 12.64 & 39.80 & 8.06 \\
TARGET & 12.70 & 12.70 & 40.00 & \\
\hline
\end{tabular}

Table 2: Measured geometrical data and weights for the 10 specimens (divided in two families) produced in the xy plane for in-plane compression tests

\begin{tabular}{lllll}
\hline Specimen (family) & $\mathrm{X}[\mathrm{mm}]$ & $\mathrm{Y}[\mathrm{mm}]$ & $\mathrm{Z}[\mathrm{mm}]$ & $\mathrm{W}[\mathrm{g}]$ \\
\hline $1(1)$ & 39.77 & 12.49 & 12.58 & 7.77 \\
$2(1)$ & 39.78 & 12.45 & 12.56 & 7.72 \\
$3(1)$ & 39.80 & 12.49 & 12.63 & 7.77 \\
$4(1)$ & 39.84 & 12.49 & 12.60 & 7.73 \\
$5(1)$ & 39.80 & 12.43 & 12.63 & 7.68 \\
$6(2)$ & 39.84 & 12.55 & 12.59 & 7.77 \\
$7(2)$ & 39.79 & 12.52 & 12.61 & 7.76 \\
$8(2)$ & 39.84 & 12.49 & 12.59 & 7.74 \\
$9(2)$ & 39.76 & 12.53 & 12.60 & 7.77 \\
$10(2)$ & 39.83 & 12.46 & 12.70 & 7.71 \\
TARGET & 40.00 & 12.70 & & 8.06 \\
\hline
\end{tabular}

Figure 4 shows the stress-strain curves for the conducted out-of-plane compression tests for the 10 proposed specimens. In each image, the linear elastic Young modulus $E_{\text {lin }}$ in $M P a$ is shown: the black line represents the linear elastic region and its slope is the linear compression Young modulus obtained by means of a linear regression. In each image included in Fig. 4, a toe point is clearly shown and it is defined as a point with a horizontal tangent between two different linear elastic regions. This toe point is created by a specimen misalignment. This misalignment is generated by a slipping in the plates, with consequent realignment with respect to the load application direction. This phenomenon is a typical mechanical test characteristic and it cannot be considered as a material characteristic. The standard reference ASTM D695 (Standard, 2015) foresees this toe point and it suggests to calculate the linear elastic Young modulus in the linear elastic region after this toe point. For all these reasons, the black line is drawn parallel to the red curve in each proposed image. The ultimate tensile strength $\sigma_{\max }$ is defined as the maximum stress value tolerable by the specimen before breaking and in the curve it is shown as the maximum value reached by the stress on the stress-strain curve. The proportional limit stress $\sigma_{\text {pro }}$ is the value where the stress-strain curve deviates by $5 \%$ from the linear behavior (the black line can be used to evaluate such a deviation). The actual values for linear elastic Young modulus $E_{\text {lin }}$, ultimate tensile strength $\sigma_{\max }$ and proportional limit stress $\sigma_{\text {pro }}$ as obtained from the curves in Fig. 4 are then summarized in Table 3 for each of the 10 specimens. In parentheses, readers can see the indication for the family 1 or the family 2 .

\section{In-Plane Compression Tests}

The experimental in-plane compression tests have been conducted on 10 specimens printed as shown in Fig. 3 with dimensions as reported in Fig. 2. The actual and target geometrical values for the 10 specimens are reported in Table 2. The experimental test type does not change with respect to the out-of-plane case. The stresses $\sigma$ in $M P a$ and the no-dimensional strains $\epsilon$ are defined in Equation (1) using the load $P$ and the displacement $\Delta L$ from the experimental activities. In the proposed cases, $w$ and $t$ are the actual dimensions of the square cross section in $Z$ and $Y$ directions, respectively; $L_{0}$ is the actual length of the specimens measured in the $X$ direction.

Such tests have been already conducted in the work (Brischetto and Torre, 2020) where readers can found all the missed details that are not here give again in order to avoid repetitions. In Brischetto and Torre (2020), the inplane compression tests have been performed on 12 specimens and all the stress-strain curves are reported to 
obtain the mechanical properties. Only mechanical properties for 10 specimens are here considered (thus discarding two specimens with respect to the work (Brischetto and Torre, 2020) in order to facilitate the comparison with the data coming from the out-of-plane compression tests. In each stress-strain curve from work (Brischetto and Torre, 2020), only the linear elastic Young modulus $E_{\text {lin }}$ in $M P a$ can be obtained because the tests were stopped when the machine arrived to the maximum applicable load $\mathrm{P}$ equals $10 \mathrm{kN}$. For this applied load, only a linear elastic region is clearly showed and no proportional limit stresses and ultimate tensile strengths can be defined in an appropriate way. For these reasons, Table 4 shows only the values of the linear elastic Young modulus $E_{\text {lin }}$ in $M P a$ for 10 specimens and then grouped in two families as indicated by parentheses ().

By comparing results in Table 3 with those in Table 4 , it is clear how the specimens are more rigid in the outof-plane direction than in the in-plane direction (Young modulus values for out-of-plane tests are bigger than those for in-plane tests). However, specimens are more resistant (even if they are less rigid) in in-plane direction because no maximum stress and proportional limit can be obtained; in fact, the test machine has reached the maximum applicable load and the stress-strain curves remain in the linear elastic region without showing any maximum value and any non-linear elastic field.

Table 3: Collected mechanical data obtained from the out-of-plane compression tests conducted on the two families of specimens produced in the xz plane

\begin{tabular}{llll}
\hline Specimen (family) & $\mathrm{E}_{\text {lin }}[\mathrm{MPa}]$ & $\sigma_{\max }[\mathrm{MPa}]$ & $\sigma_{\text {pro }}[\mathrm{MPa}]$ \\
\hline $1(1)$ & 2587.6 & 83.9 & 80.7 \\
$2(1)$ & 2456.6 & 76.0 & 73.7 \\
$3(1)$ & 2513.0 & 83.4 & 80.9 \\
$4(1)$ & 2608.3 & 84.2 & 83.9 \\
$5(1)$ & 2672.3 & 88.2 & 84.8 \\
$6(2)$ & 2639.5 & 88.0 & 88.0 \\
$7(2)$ & 2512.6 & 86.3 & 83.6 \\
$8(2)$ & 2603.6 & 83.5 & 82.0 \\
$9(2)$ & 2532.7 & 86.0 & 86.0 \\
$10(2)$ & 2649.7 & 85.0 & 85.0 \\
\hline
\end{tabular}

Table 4: Collected mechanical data obtained from the in-plane compression tests conducted on the two families of specimens produced in the xy plane

\begin{tabular}{llll}
\hline Specimen (family) & $\mathrm{E}_{\text {lin }}[\mathrm{MPa}]$ & $\sigma_{\max }[\mathrm{MPa}]$ & - \\
\hline $1(1)$ & 2053.4 & - & - \\
$2(1)$ & 2041.0 & - & - \\
$3(1)$ & 2027.5 & - & - \\
$4(1)$ & 2026.8 & - & - \\
$5(1)$ & 2031.5 & - & - \\
$6(2)$ & 1990.4 & - & - \\
$7(2)$ & 2048.5 & - & - \\
$8(2)$ & 2016.4 & - & - \\
$9(2)$ & 2033.1 & - & - \\
$10(2)$ & 2023.5 & - & - \\
\hline
\end{tabular}
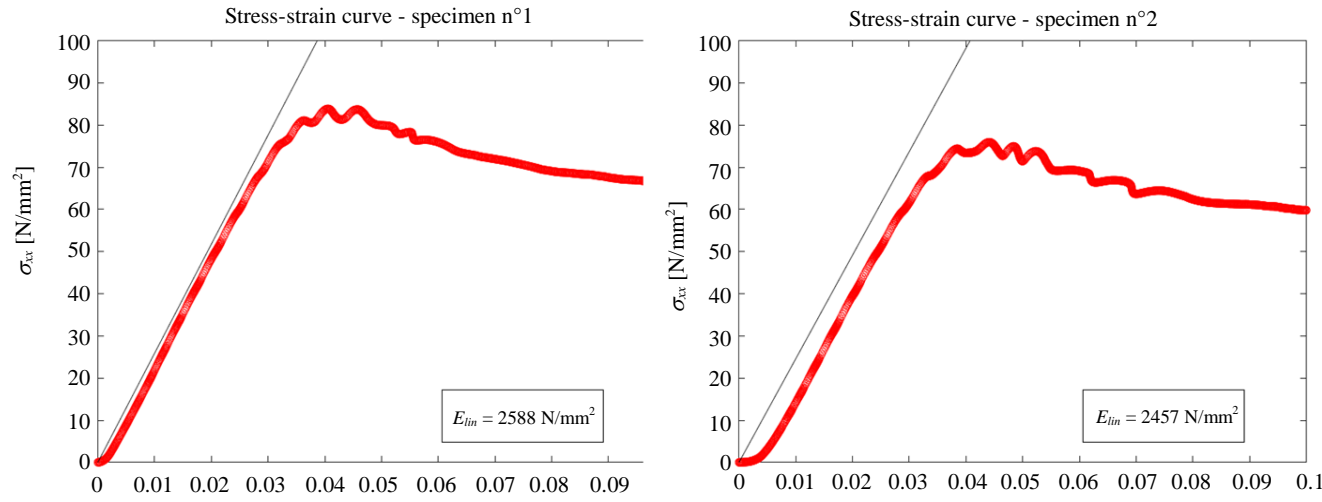

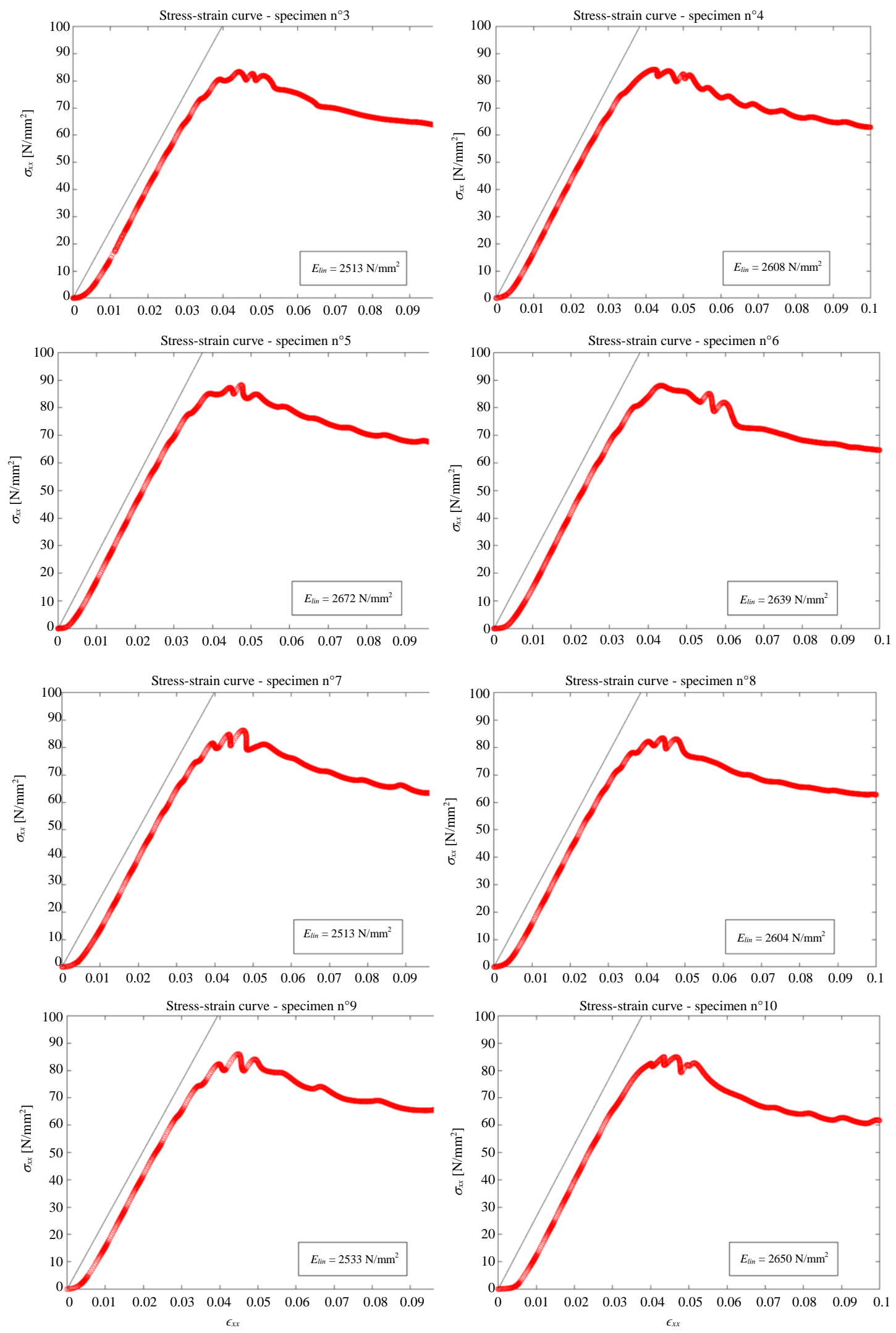

Fig. 4: Stress-strain curves for the 10 specimens produced in the xz plane and subjected to out-of-plane compression tests 


\section{Statistical and Capability Analysis}

This section is devoted to the statistical and capability analysis of the collected experimental data for both out-of-plane and in-plane compression tests. It is divided in two main parts: the first part shows the analysis for the geometrical data of the specimens with the opportune comparisons between the two cases of out-of-plane and in-plane 3D printing; the second part gives the analysis for the mechanical properties obtained from both the out-of-plane and in-plane compression tests and the related comparisons in terms of structural rigidity and strength.

\section{Geometrical Data Comparison}

Table 1 proposes the measured geometrical data and weights for the 10 produced specimens in out-of-plane direction. The printed specimens have been also divided in two different families as already explained in previous sections. The last line shows the related target values as given by the CAD draw. The same data types are given in Table 2 for the 10 printed specimens in the in-plane direction, the same family groupings are considered in parentheses. These collected data can be analyzed by means of an appropriate capability analysis if they can be represented via a Gaussian normal distribution (Brischetto et al., 2019). For the case of out-of-plane printed specimens, this information is provided by the Anderson Darling value (AD-value) and the Probability index (P-index) shown in Figures 58 and then summarized in Table 5. When low values for $\mathrm{AD}$ are determined, the proposed data can be successfully analyzed by using a Gaussian normal distribution. Moreover, this consideration can be further confirmed via the determination of an high value for the $\mathrm{P}$-index (this index varies from 0 to 1 and it must be usually greater than an opportune threshold value that has been here set equals 0.05). For all the three dimensions $X, Y$ and $Z$ and the weight $\mathrm{W}$ in Table 5 , even if the $A D$ value is not always so low, however the $\mathrm{P}$-index is great enough to confirm the use of a Gaussian normal distribution. By using a normal distribution, it is possible to define a mean value $\mu$ for each parameter and a related standard deviation $\hat{\sigma}$. Such an analysis can be performed in the long period (for all the 10 specimens) or in a short period (for two separated families, each one comprising 5 specimens). A printing process is usually more stable in the short period because there are fewer disturbing elements in the process, this feature can be seen by observing the values for the standard deviation and/or the form of the Gaussian curves in the figures. A more stable process has smaller values for the standard deviation $\hat{\sigma}$ and narrower and higher Gaussian curves. However, this consideration is not always so evident in Table 5 and in
Figures 5-8 because of the small dimension of the specimens and their low number. By focusing in the long period, if we define for each geometrical parameter a mean value $\mu$ and a standard deviation $\hat{\sigma}$, it is possible (by supposing a $\hat{\sigma}$-level equals 4) to define a range between an Upper Speciation Limit (USL) and a Lower Speciation Limit (LSL) thanks the following equations:

$U S L=\mu+4 \hat{\sigma}$

$L S L=\mu+4 \hat{\sigma}$.

In Fig. 5 and in the first column of Table 5, one of the two dimensions of the square cross section (here defined in the $\mathrm{X}$ direction) has mean value equals $12.7990 \mathrm{~mm}$ with standard deviation equals 0.073401 $\mathrm{mm}, \mathrm{LSL}=12.05054 \mathrm{~mm}$ and USL $=13.0926 \mathrm{~mm}$. The target value is $12.70 \mathrm{~mm}$, it is very close to the mean value and inside the range defined between the LSL and the USL.

The other dimension of the square cross section is defined in the $Y$ direction and then analyzed in Fig. 6 and in the second column of Table 5. The mean value is $12.6900 \mathrm{~mm}$ having a standard deviation $\hat{\sigma}=$ $0.075572 \mathrm{~mm}$. By using a $\hat{\sigma}$-level equals 4 , the LSL is $12.3877 \mathrm{~mm}$ and the USL is $12.9923 \mathrm{~mm}$. The target value $12.70 \mathrm{~mm}$ is almost coincident with the mean value and it is perfectly inside the interval between the LSL and the USL.

Figure 7 and the third column of Table 5 propose the statistical and capability analysis of the length in the $Z$ direction. The mean value is $39.8460 \mathrm{~mm}$ and the standard deviation is $0.062752 \mathrm{~mm}$. The target value equals $40.00 \mathrm{~mm}$. A $\hat{\sigma}$-level equals 4 means $\mathrm{LSL}=39.59550 \mathrm{~mm}$ and $\mathrm{USL}=40.0970 \mathrm{~mm}$. Even if the target value is inside the range between the USL and the LSL, it is far from the mean value. This feature means that the printing process in this direction could be improved, for example by means of an opportune re-scaling of the draw using the difference in percentage between the mean value and the target value.

The statistical and capability analysis for the weight $\mathrm{W}$ is proposed in Fig. 8 and in the last column of Table 5. The mean value is $7.8900 \mathrm{~g}$ with standard deviation equals $0.053955 \mathrm{~g}$. By imposing $\hat{\sigma}$-level equals 4 , the LSL is $7.6742 \mathrm{~g}$ an the USL is $8.1058 \mathrm{~g}$. The target value equals $8.06 \mathrm{~g}$ is between the USL and the LSL but it is quite far from the mean value. An improvement in the definition of the weight of each specimen is not so easy because this parameter depends on the quantity of extruded material and also by the three dimensions in the $X, Y$ and $Z$ directions. 

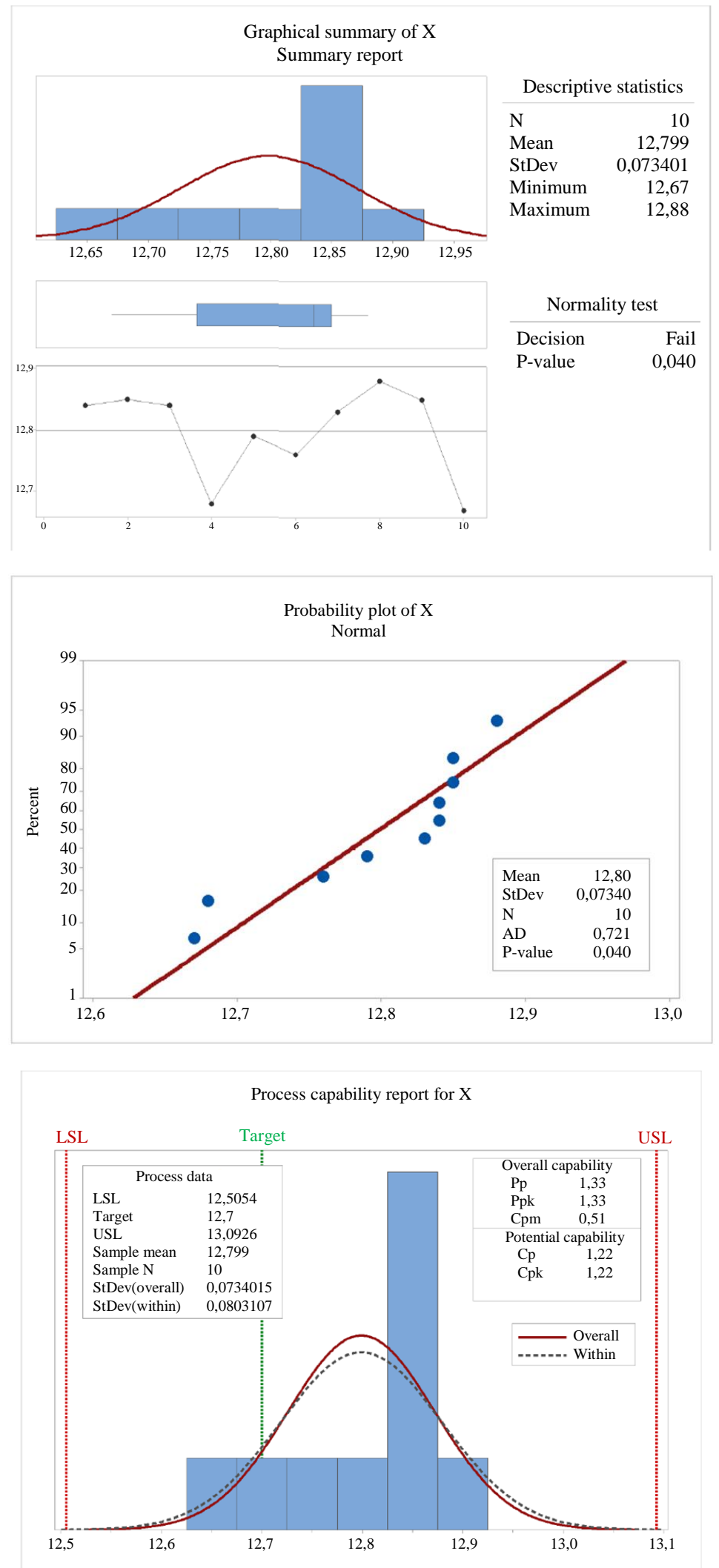

Fig. 5: Graphical summary, probability plot and process capability report for the dimension $\mathrm{X}$ of specimens printed in the xz plane for out-of-plane compression tests 

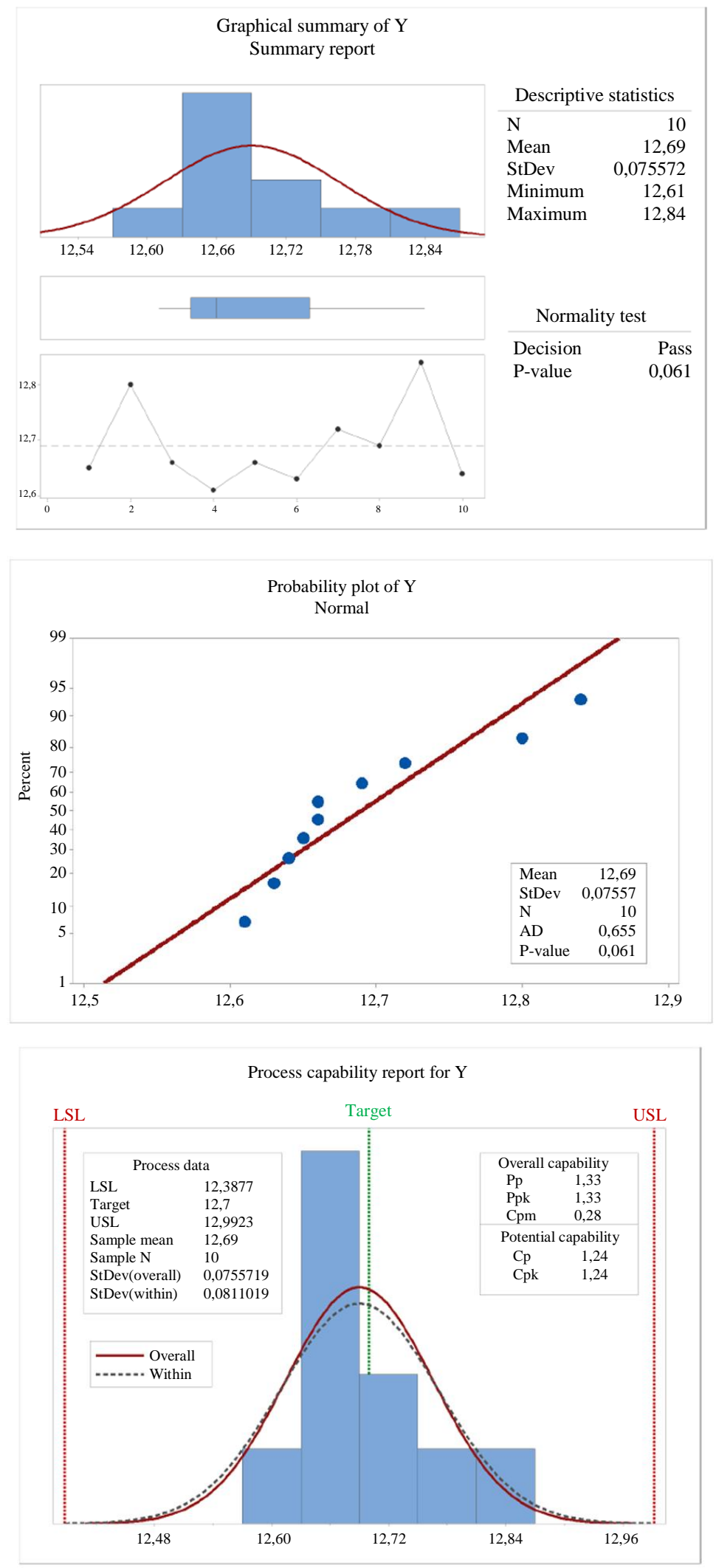

Fig. 6: Graphical summary, probability plot and process capability report for the dimension $\mathrm{Y}$ of specimens printed in the $\mathrm{xz}$ plane for out-of-plane compression tests 

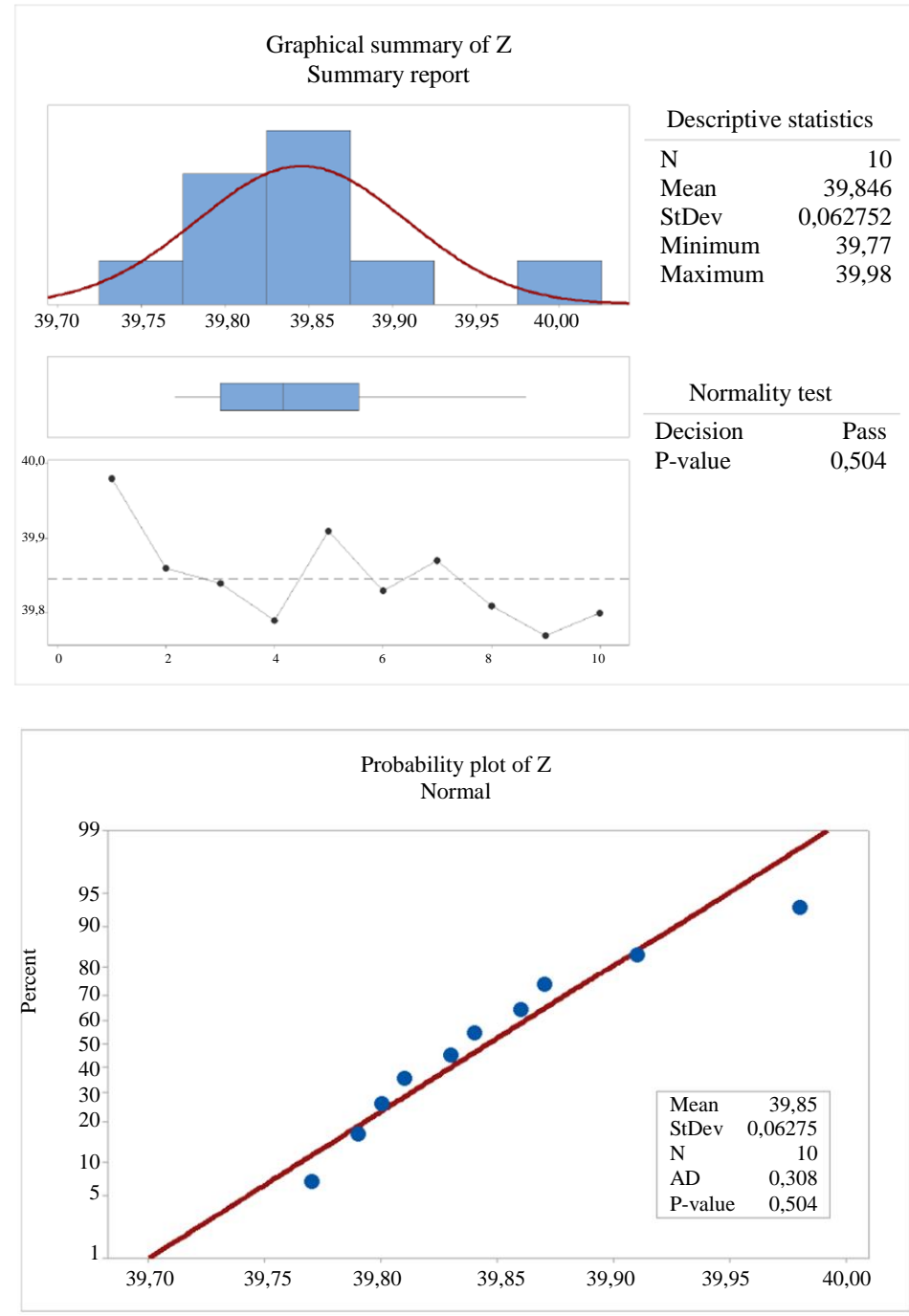

Process capability report for Z

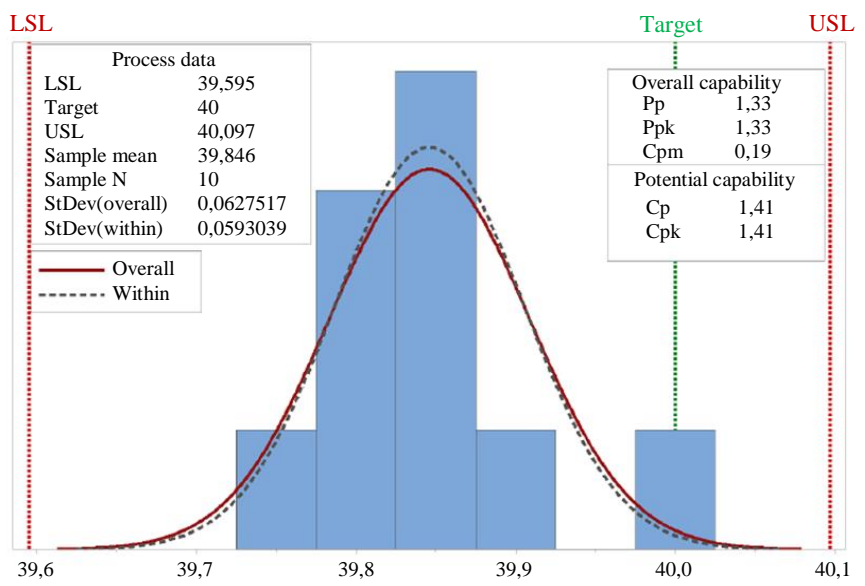

Fig. 7: Graphical summary, probability plot and process capability report for the dimension $Z$ of specimens printed in the $x z$ plane for out-of-plane compression tests 

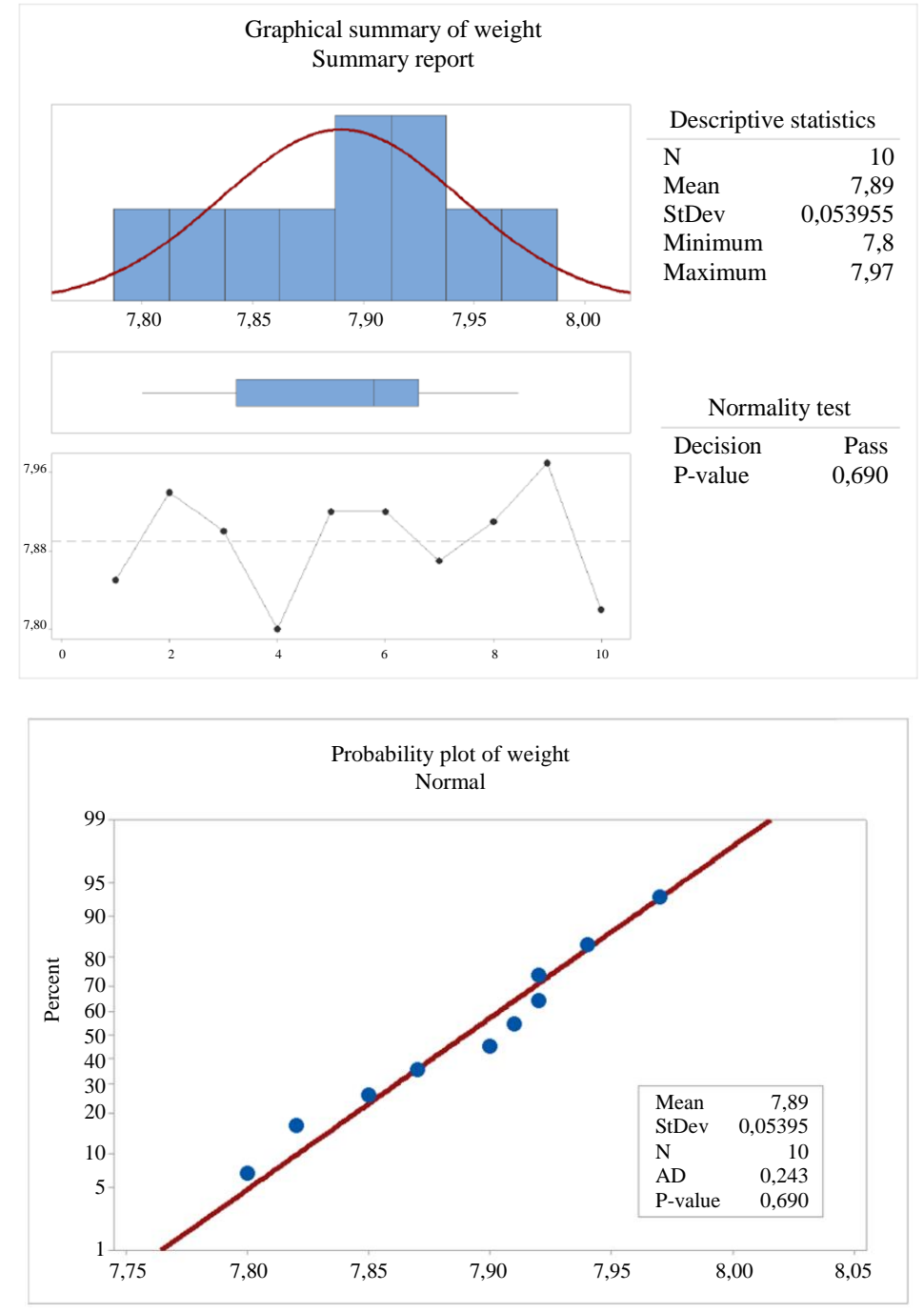

Process capability report for weight

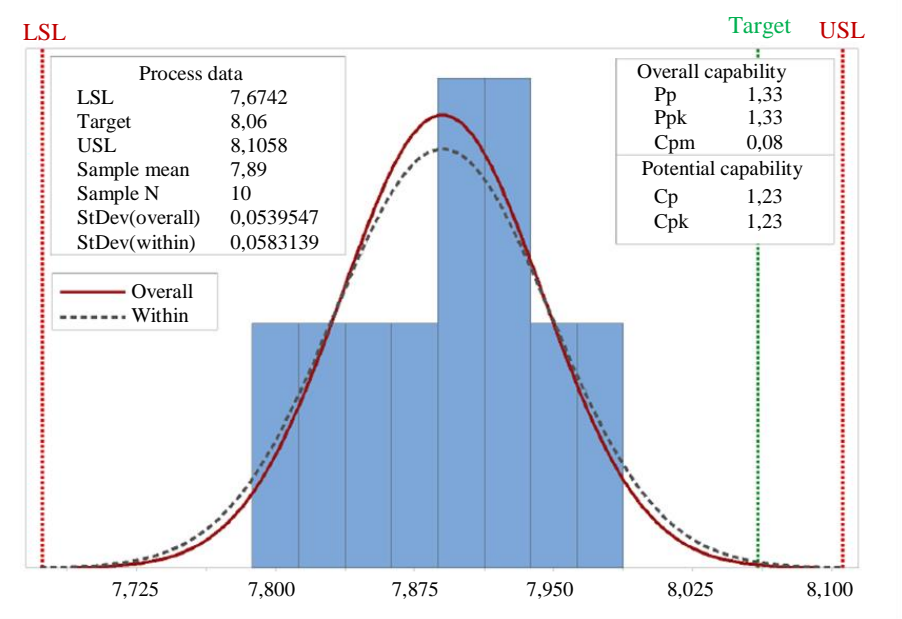

Fig. 8: Graphical summary, probability plot and process capability report for the weight $\mathrm{W}$ of specimens printed in the xz plane for out-of-plane compression tests 
Table 5: Summary of the capability analysis for the dimensions and weight of the 10 specimens produced in the xz plane for out-ofplane compression tests

\begin{tabular}{lrrrr}
\multicolumn{1}{c}{ plane compression tests } & $\mathrm{X}$ & $\mathrm{Y}$ & $\mathrm{Z}$ & $\mathrm{W}$ \\
\hline & & & & \\
All the 10 specimens & 12.799000 & 12.690000 & 39.846000 & 7.890000 \\
Mean value $\mu$ & 0.073401 & 0.075572 & 0.062752 & 0.053955 \\
Stand. dev. $\hat{\sigma}$ & 12.505400 & 12.387700 & 39.595000 & 7.674200 \\
LSL & 13.092600 & 12.992300 & 40.097000 & 8.105800 \\
USL & 0.721000 & 0.655000 & 0.308000 & 0.243000 \\
AD-value & 0.040000 & 0.061000 & 0.504000 & 0.690000 \\
P-value & & & 39.876000 & 7.882000 \\
The first five specimens of the family $\mathbf{1}$ & 12.676000 & 0.072319 & 0.056745 \\
Mean value $\mu$ & 12.800000 & 0.072319 & & \\
Stand. dev. $\hat{\sigma}$ & 0.071063 & & 39.816000 & 7.898000 \\
The second five specimens of the family $\mathbf{2}$ & 12.798000 & 12.704000 & 0.037148 & 0.056303 \\
Mean value $\mu$ & 0.084083 & 0.084439 & & \\
Stand. dev. $\hat{\sigma}$ & & &
\end{tabular}

Table 6: Summary of the capability analysis for the dimensions and weight of the 10 specimens produced in the xy plane for inplane compression tests

\begin{tabular}{lrrrr}
\hline & \multicolumn{1}{c}{ X } & \multicolumn{1}{c}{ Y } & Z & W \\
\hline All the 10 specimens & & & & \\
Mean value $\mu$ & 39.803200 & 12.488500 & 12.597300 & 7.741900 \\
Stand. dev. $\hat{\sigma}$ & 0.031412 & 0.037457 & 0.021999 & 0.031235 \\
LSL & 39.677500 & 12.338700 & 12.509300 & 7.617000 \\
USL & 39.928800 & 12.638300 & 12.685200 & 7.866900 \\
AD-value & 0.488000 & 0.267000 & 0.167000 & 0.452000 \\
P-value & 0.180000 & 0.619000 & 0.916000 & 0.225000 \\
The first five specimens of the family $\mathbf{1}$ & & & & \\
Mean value $\mu$ & 39.795700 & 12.469000 & 12.590500 & 7.734000 \\
Stand. dev. $\hat{\sigma}$ & 0.027628 & 0.028864 & 0.027295 & 0.036377 \\
The second five specimens of the family $\mathbf{2}$ & & & \\
Mean value $\mu$ & 39.810700 & 12.508000 & 12.604000 & 7.749900 \\
Stand. dev. $\hat{\sigma}$ & 0.036278 & 0.037056 & 0.015166 & 0.026726 \\
\hline
\end{tabular}

The capability and statistical analysis for dimensions and weight of specimens printed in in-plane directions was already performed in (Brischetto and Torre, 2020) and it is here summarized in Table 6 for comparison purposes with the printing of specimens in out-of-plane directions. More details, in particular the graphical summaries, the probability plots and the process capability reports, can be found in (Brischetto and Torre, 2020). The length of the specimen is now printed in the $X$ direction and the dimensions of the square cross section are now in $Y$ and $Z$ directions. For all the dimensions and the weight, even if the $A D$-value is not so low, the P-index is high enough to confirm the use of a Gaussian normal distribution for such data. By comparing the standard deviation in the long and short periods, it is not so clear that the process is more stable in the short period with respect to the long period. The explanation for this feature is the same already given for the specimens printed in out-of-plane directions. In Tables 6 and 2, it is clear how the target values for the dimensions in $X, Y$ and $Z$ directions are now always out of the ranges between the $U S L$ and $L S L$ even if they are not so far from the mean values. A partial explanation for this feature could be the determination of smaller ranges because the standard deviations are now lower. Therefore, this could be a partial positive feature. The considerations for the weight are similar to those already made for the out-of-plane case even if now the dispersion is smaller because the standard deviation is lower than that for the weight of the out-of-plane printed specimens. The actions to improve the printing process are the same already explained for the case of out-of-plane printing.

From a comparison between Tables 5 and 6, it is clear how in general the printing in the $X$ direction of the length $L_{0}$ of in-plane printed specimens has a smaller standard deviation than that for the printing in the $Z$ direction of the length $L_{0}$ of out-of-plane printed specimens. The target value is always $40 \mathrm{~mm}$. This feature is due to the fact that printing of the length in the $X$ direction is obtained by the moving of the extruder from a starting point to an arriving point, while the length in the $Z$ direction is obtained as a summation of several deposited layers. This second process is obviously a less precise process. The standard deviations for the two dimensions of the square cross sections and for the weight are smaller for the in-plane 
printed specimens even if the mean values are more distant from the target values.

In conclusions, the two printing processes (in inplane and out-of-plane directions) are quite stable even if they can be both improved by means of opportune rescalings of the draws using the differences in percentage between the target and the mean values. Because of the small dimensions of the specimens and their reduced number, in both cases it cannot be noticed a greater stability of the process in the short period with respect to the long period. In the two printing processes, some dimensions are more accurate than others depending how they have been printed, for example as summation of deposited layers or as moving of the extruder between two given points.

\section{Mechanical Data Comparison}

The mechanical data for out-of-plane compression tests collected in Table 3 are the linear elastic Young modulus $E_{\text {lin }}$, the ultimate tensile strength $\sigma_{\max }$ and the proportional limit stress $\sigma_{\text {pro }}$. Their statistical and capability analysis has been performed by means of Figures 9-11 and Table 7. The mechanical data for in- plane compression tests are given in Table 4 where only linear elastic Young modulus $E_{\text {lin }}$ is reported because all the 10 tests reached the maximum applicable load by the test machine $(\mathrm{P}=10 \mathrm{kN})$ showing only a linear elastic region for the $\sigma-\epsilon$ curves without arriving to the ultimate tensile strength and without highlighting any proportional limit stress. The statistical and capability analysis for the mechanical properties of in-plane compression tests was already performed in (Brischetto and Torre, 2020) where the readeres can find all the necessary details. However, Table 8 gives a summary of this analysis.

In the case of out-of-plane compression tests (Table 7), all the mechanical properties can be studied by means of a Gaussian distribution because of the calculated values for the $\mathrm{AD}$-value and the $\mathrm{P}$-index. By comparing the standard deviations for the long and short periods, it was not demonstrated a bigger stability for the short periods: the reasons have been already explained in the previous section for the dimensional studies. Similar considerations are valid for the linear elastic Young modulus investigated in Table 8 for the in-plane-compression tests.

Table 7: Summary of the capability analysis for the mechanical properties of the 10 specimens produced in the $x z$ plane and subjected to the out-of-plane compression test

\begin{tabular}{lrrr}
\hline & \multicolumn{1}{c}{$\mathrm{E}_{\text {lin }}$} & \multicolumn{1}{c}{$\sigma_{\max }$} & $\sigma_{\text {pro }}$ \\
\hline All the 10 specimens & & & 82.860000 \\
Mean value $\mu$ & 2577.590000 & 84.450000 & 3.935649 \\
Stand. dev. $\hat{\sigma}$ & 70.531135 & 3.441011 & 67.117400 \\
LSL & 2295.465500 & 70.686000 & 98.602600 \\
USL & 2859.714500 & 98.214000 & 0.449000 \\
AD-value & 0.280000 & 0.665000 & 0.218000 \\
P-value & 0.562000 & 0.057000 & 80.800000 \\
The first five specimens of the family $\mathbf{}$ & & & 4.360046 \\
Mean value $\mu$ & 2567.560000 & 83.140000 & \\
Stand. dev. $\hat{\sigma}$ & 84.143823 & 4.425833 & 84.920000 \\
The second five specimens of the family 2 & & & 2.287357 \\
Mean value $\mu$ & 2587.620000 & 85.760000 & 1.662227 \\
Stand. dev. $\hat{\sigma}$ & 62.139014 & & \\
\hline
\end{tabular}

Table 8: Summary of the capability analysis for the mechanical properties of the 10 specimens produced in the xy plane and subjected to the in-plane compression test

\begin{tabular}{lr}
\hline All the 10 specimens & Elin \\
Mean value $\mu$ & 2029.210000 \\
Stand. dev. $\hat{\sigma}$ & 17.727220 \\
LSL & 1958.301100 \\
USL & 2100.118900 \\
AD-value & 0.444000 \\
P-value & 0.230000 \\
The first five specimens of the family $\mathbf{1}$ & 2036.040000 \\
Mean value $\mu$ & 11.234901 \\
Stand. dev. $\hat{\sigma}$ & \\
The second five specimens of the family $\mathbf{2}$ & 2022.380000 \\
Mean value $\mu$ & 21.545928 \\
Stand. dev. $\hat{\sigma}$ &
\end{tabular}



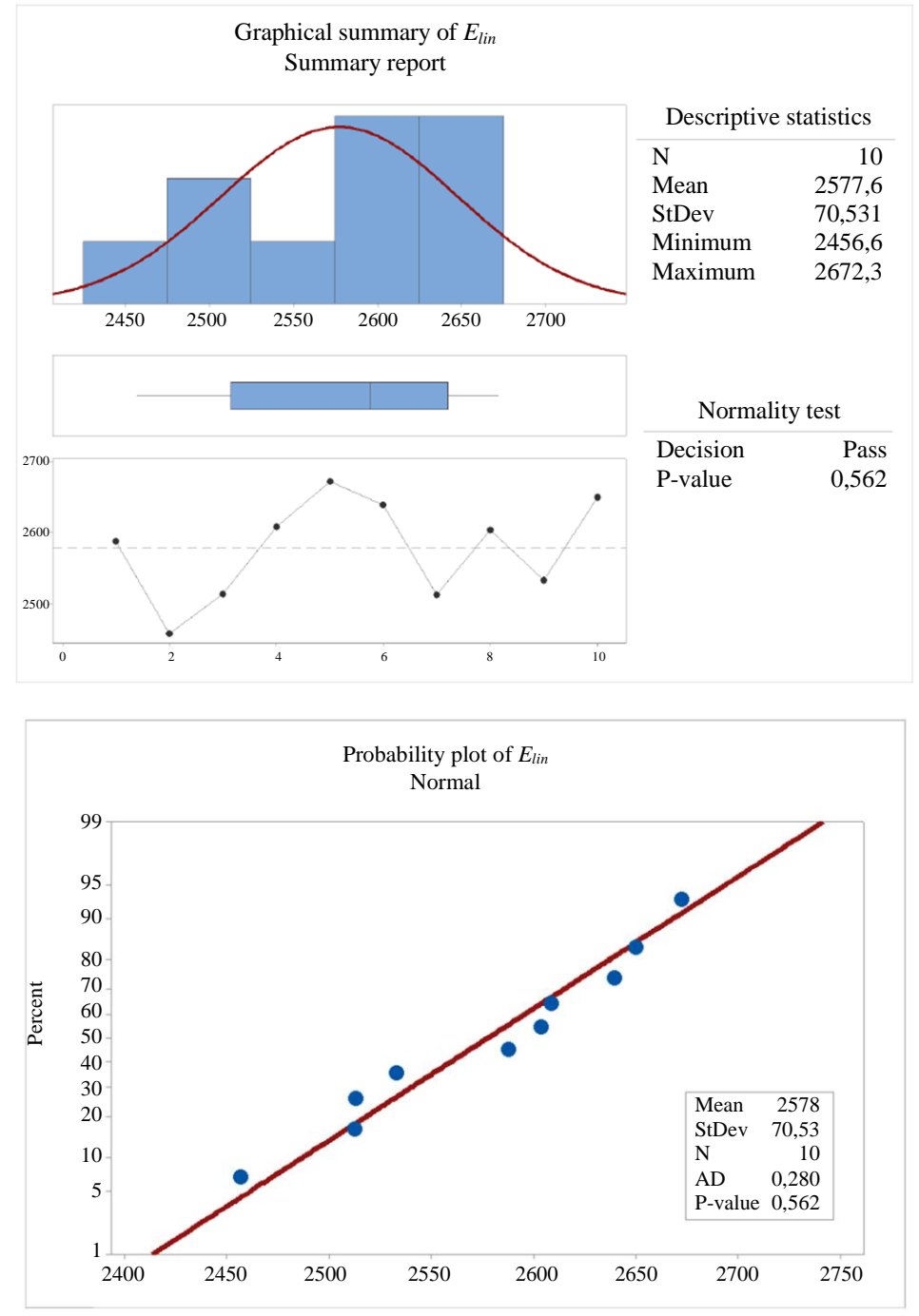

Process capability report for $E_{\text {lin }}$

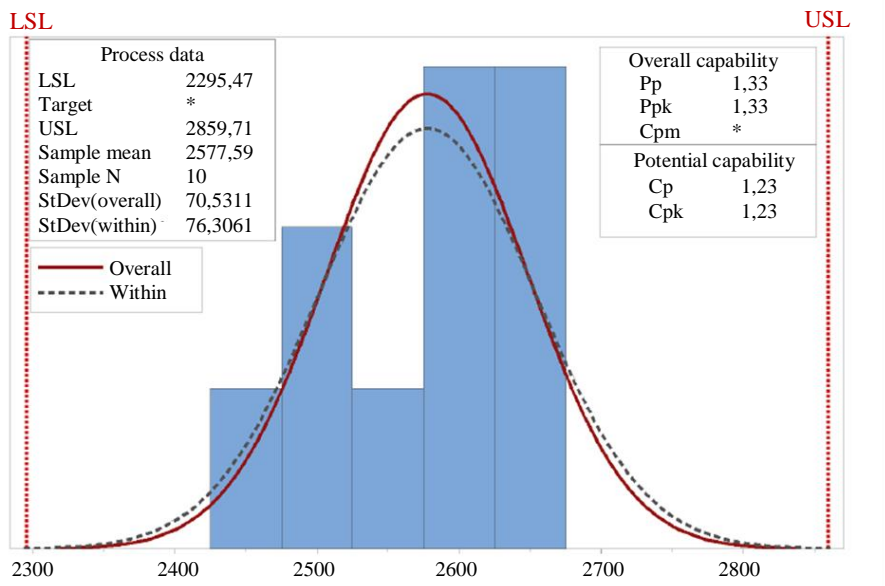

Fig. 9: Graphical summary, probability plot and process capability report for the linear elastic Young modulus Elin of specimens printed in the xz plane for out-of-plane compression tests 

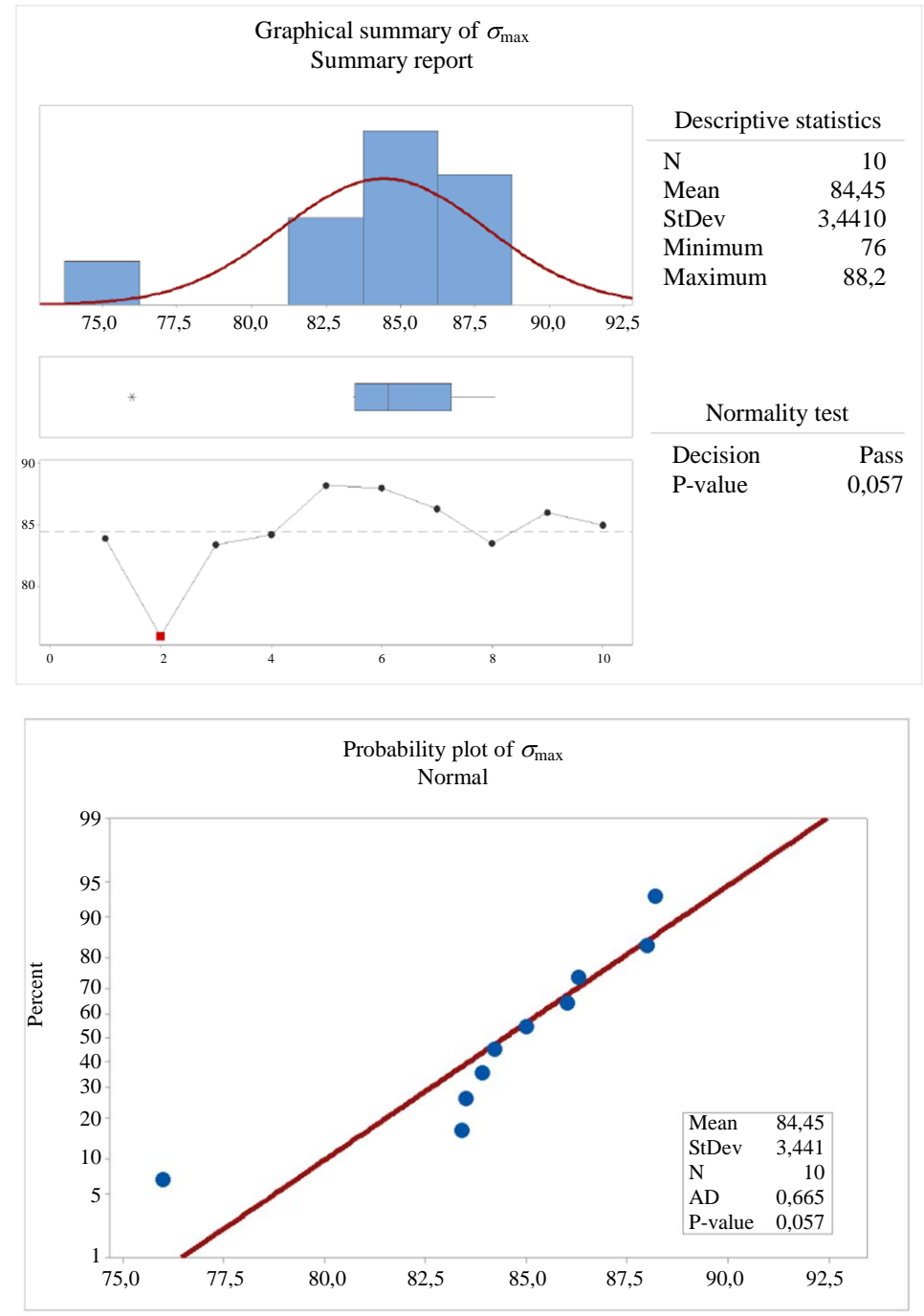

Process capability report for $\sigma_{\max }$

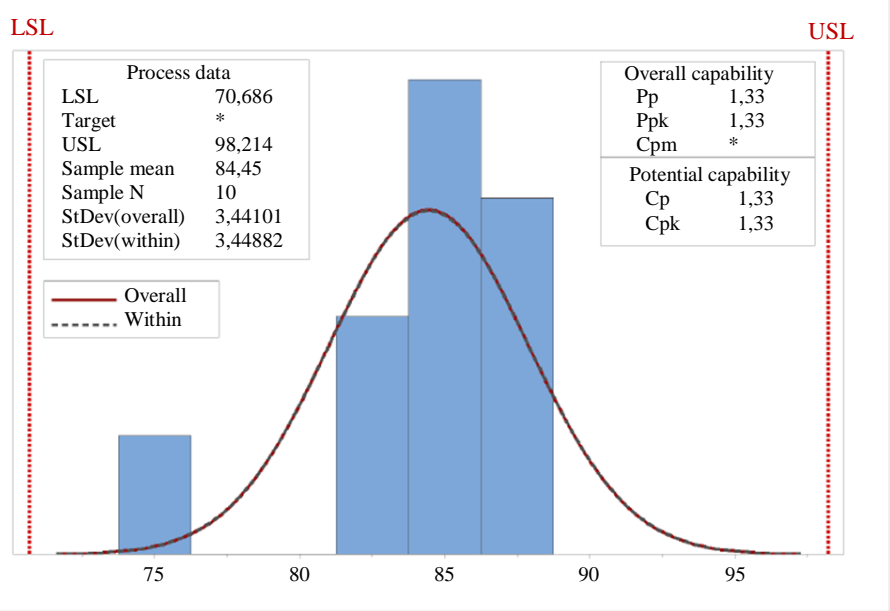

Fig. 10: Graphical summary, probability plot and process capability report for the maximum strength $\sigma_{\max }$ of specimens printed in the xz plane for out-of-plane compression tests 

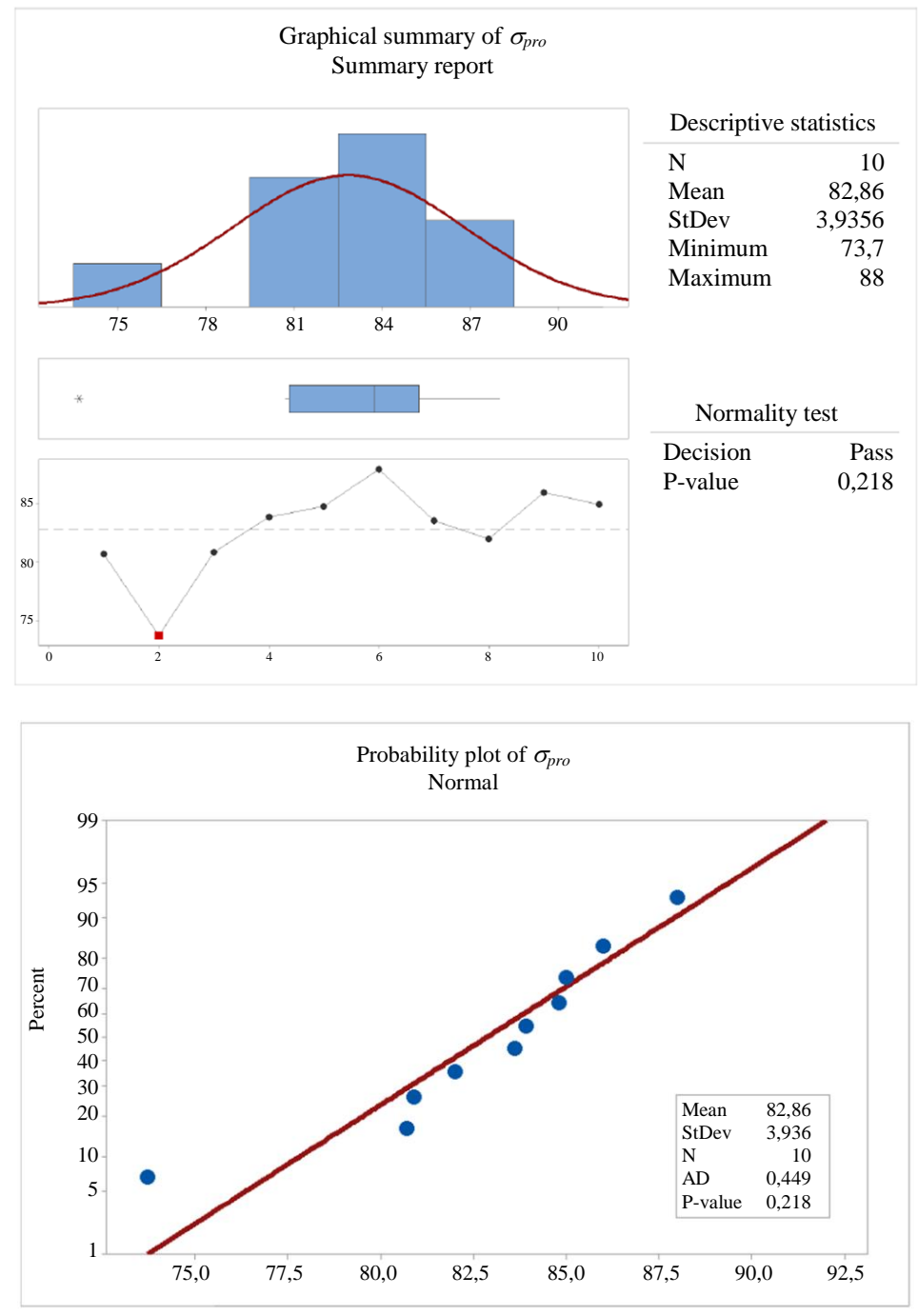

Process capability report for $\sigma_{\text {pro }}$

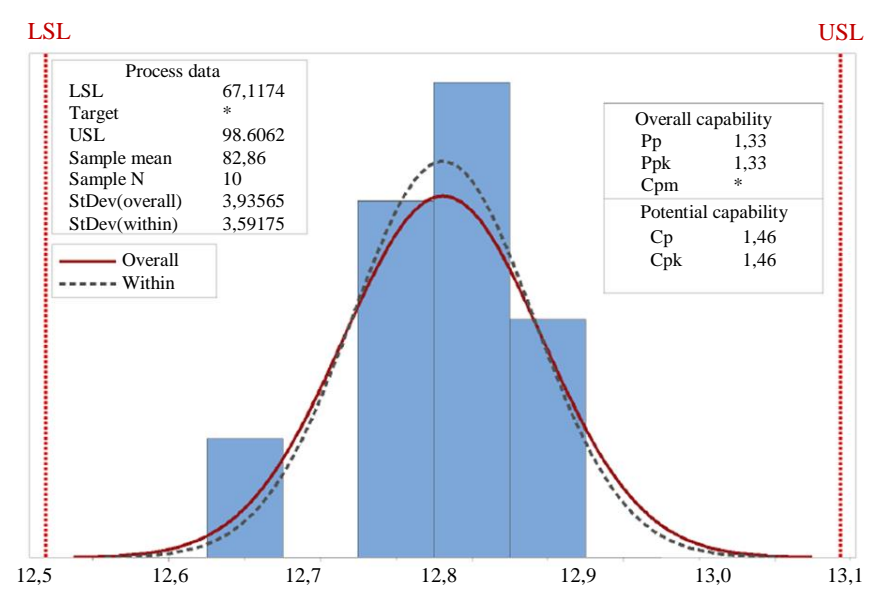

Fig. 11: Graphical summary, probability plot and process capability report for the proportional limit stress $\sigma_{\text {pro }}$ of specimens printed in the xz plane for out-of-plane compression tests 
Figures 9-11 and Table 7 show the mean values and the standard deviations for the linear elastic Young modulus $E_{\text {lin }}$, the ultimate tensile strength $\sigma_{\max }$ and the proportional limit stress $\sigma_{\text {pro. }}$ By imposing a $\hat{\sigma}$-level equals 4, appropriate USL and LSL are defined giving opportune ranges. No target values are possible for the mechanical properties because they have been here defined for the first time. USL and LSL can be used as design values depending on the type of conducted structural analysis.

The specimens printed in out-of-plane directions are more rigid than specimens printed in in-plane directions: the mean value for $E_{\text {lin }}$ in Table 7 is $2577.59 \mathrm{MPa}$ while the mean value for $E_{\text {lin }}$ in Table 8 is 2029.21 MPa. However, the specimens printed in in-plane directions are more resistent because we cannot define any values for the ultimate tensile strength $\sigma_{\max }$ and for the proportional limit stress $\sigma_{\text {pro }}$ even if the test machine arrive to the maximum applicable load $\mathrm{P}=10 \mathrm{kN}$. The specimens printed in outof-plane directions are less resistent because even if we use the same test machine, we are able to define values for the ultimate tensile strength and for the proportional limit stress. From Table 7, the mean value for the ultimate tensile strength $\sigma_{\max }$ is $84.45 \mathrm{MPa}$ and the mean value for the proportional limit stress $\sigma_{\text {pro }}$ is $82.86 \mathrm{MPa}$.

\section{Conclusion}

This paper proposed a comparison between compression tests conducted for PLA specimens 3D printed in out-of-plane directions and PLA specimens 3D printed in in-plane directions. The employed 3D printing technology was the Fused Deposition Modeling (FDM). The printed specimens were measured and weighed and the collected data were analyzed by means of appropriate statistical and capability analyses. By using a Gaussian normal distribution, mean values and standard deviations were calculated for the three dimensions in $X, Y$ and $Z$ directions and for the weight $\mathrm{W}$. The imposition of $\hat{\sigma}$-level equals 4 allowed the definition of an appropriate range between the Lower Speciation Limit (LSL) and the Upper Speciation Limit (USL). The target values obtained from the CAD draws were compared with the mean values and with the limit of acceptance given by the LSL and USL values. No significant differences were found for the printing procedures performed in the in-plane or in the outof-plane directions and all the printing processes resulted quite stable even if they could be improved by means of opportune draw re-scalings performed using the differences in percentage between mean and target values.

Then, the specimens were tested in compression in order to obtain the linear elastic Young modulus $E_{\text {lin }}$, the ultimate tensile strength $\sigma_{\max }$ and the proportional limit stress $\sigma_{\text {pro. }}$. For these mechanical properties, opportune capability and statistical analyses were conducted using a Gaussian normal distribution in order to find mean values and related standard deviations. Appropriate LSL and
USL values were found by imposing a $\hat{\sigma}$-level equals 4 , these limits could be used as tentative design values. The specimens printed and tested in out-of-plane directions had a mean value for the linear elastic Young modulus $E_{\text {lin }}$ equals 2577.59 $\mathrm{MPa}$. The specimens printed and tested in in-plane directions were less rigid because their mean value for the linear elastic Young modulus $E_{\text {lin }}$ was equal to $2029.21 \mathrm{MPa}$. However, these last specimens were more resistent. In fact, the ultimate tensile strength $\sigma_{\max }$ and the proportional limit stress $\sigma_{\text {pro }}$ were not defined for in-plane printed specimens because the test machine arrived to its maximum applicable load $\mathrm{P}=10 \mathrm{kN}$ and the related $\sigma-\epsilon$ curves showed no maximum values for stress and any deviation from the linear elastic behavior. On the contrary, for the specimens printed and tested in out-ofplane directions, the mean value for the ultimate tensile strength $\sigma_{\max }$ was $84.45 \mathrm{MPa}$ and the mean value for the proportional limit stress $\sigma_{\text {pro }}$ was $82.86 \mathrm{MPa}$.

\section{Acknowledgment}

No financial support in particular should be thanked in the production of this work.

\section{Author's Contributions}

Salvatore Brischetto: Conceptualization, methodology, software, validation, investigation, writing-original draft preparation, writing-review and editing.

Roberto Torre: Conceptualization, methodology, software, validation, investigation, writing-original draft preparation, writing-review and editing.

All authors have read and agreed to the published version of the manuscript.

\section{Ethics}

No conflicts of interest and no ethical problems can be found in the production of this work.

\section{References}

Abbot, D. W., Kallon, D. V. V., Anghel, C., \& Dube, P. (2019). Finite Element Analysis of 3D Printed Model via Compression Tests. Procedia Manufacturing, 35, 164-173.

Abeykoon, C., Sri-Amphorn, P., \& Fernando, A. (2020). Optimization of fused deposition modeling parameters for improved PLA and ABS 3D printed structures. International Journal of Lightweight Materials and Manufacture, 3(3), 284-297.

Bici, M., Brischetto, S., Campana, F., Ferro, C. G., Seclì, C., Varetti, S., ... \& Mazza, A. (2018). Development of a multifunctional panel for aerospace use through SLM additive manufacturing. Procedia CIRP, 67, 215-220. 
Brischetto, S., \& Torre, R. (2020). Tensile and Compressive Behavior in the Experimental Tests for PLA Specimens Produced via Fused Deposition Modelling Technique. Journal of Composites Science, 4, 140.

Brischetto, S., Ciano, A., \& Ferro, C. G. (2016). A multipurpose modular drone with adjustable arms produced via the FDM additive manufacturing process. Curved and Layered Structures, 1(open-issue).

Brischetto, S., Ciano, A., \& Ferro, C. G. (2018a). A multipurpose modular drone with adjustable arms produced via the FDM additive manufacturing process. Curved and Layered Structures, 1(open-issue).

Brischetto, S., Ferro, C. G., Torre, R., \& Maggiore, P. (2018b). 3D FDM production and mechanical behavior of polymeric sandwich specimens embedding classical and honeycomb cores. Curved and Layered Structures, 5(1), 80-94.

Brischetto, S., Maggiore, P., \& Ferro, C. G. (Eds.). (2018c). Additive Manufacturing Technologies and Applications. MDPI.

Brischetto, S., Ferro, C. G., Maggiore, P., \& Torre, R. (2017a). Compression tests of ABS specimens for UAV components produced via the FDM technique. Technologies, 5(2), 20.

Brischetto, S., Maggiore, P., \& Ferro, C. G. (2017b). Special Issue on "Additive Manufacturing Technologies and Applications".

Brischetto, S., Torre, R., \& Ferro, C. G. (2019, July). Experimental evaluation of mechanical properties and machine process in fused deposition modelling printed polymeric elements. In International Conference on Applied Human Factors and Ergonomics (pp. 377-389). Springer, Cham.

Chacón, J. M., Caminero, M. A., García-Plaza, E., \& Núnez, P. J. (2017). Additive manufacturing of PLA structures using fused deposition modelling: Effect of process parameters on mechanical properties and their optimal selection. Materials \& Design, 124, 143-157.

Corapi, D., Morettini, G., Pascoletti, G., \& Zitelli, C. (2019). Characterization of a Polylactic acid (PLA) produced by Fused Deposition Modeling (FDM) technology. Procedia Structural Integrity, 24, 289-295.

Croccolo, D., De Agostinis, M., \& Olmi, G. (2013). Experimental characterization and analytical modelling of the mechanical behaviour of fused deposition processed parts made of ABS-M30. Computational Materials Science, 79, 506-518.

Dal Maso, A., \& Cosmi, F. (2018). Mechanical characterization of 3D-printed objects. Materials Today: Proceedings, 5(13), 26739-26746.

Dev, S., \& Srivastava, R. (2020). Experimental investigation and optimization of FDM process parameters for material and mechanical strength. Materials Today: Proceedings.
Dhinesh, S. K., Arun, P. S., Senthil, K. K., \& Megalingam, A. (2020). Study on flexural and tensile behavior of PLA, ABS and PLA-ABS materials. Materials Today: Proceedings.

Ezeh, O. H., \& Susmel, L. (2018). On the fatigue strength of 3D-printed polylactide (PLA). Procedia Structural Integrity, 9, 29-36.

Ferreira, R. T. L., Amatte, I. C., Dutra, T. A., \& Bürger, D. (2017). Experimental characterization and micrography of 3D printed PLA and PLA reinforced with short carbon fibers. Composites Part B: Engineering, 124, 88-100.

Ferro, C. G., Brischetto, S., Torre, R., \& Maggiore, P. (2016). Characterization of ABS specimens produced via the $3 \mathrm{D}$ printing technology for drone structural components. Curved and Layered Structures, 1(open-issue).

Ferro, C. G., Casini, A. E. M., Mazza, A., Maggiore, P., \& Brischetto, S. (2017, September). A novel design approach for space components: application to a multifunctional panel. In 68th International Astronautical Congress (IAC), Adelaide (Australia) (pp. 25-29).

Galantucci, L. M., Lavecchia, F., \& Percoco, G. (2008). Study of compression properties of topologically optimized FDM made structured parts. CIRP annals, 57(1), 243-246.

Garzon-Hernandez, S., Garcia-Gonzalez, D., Jérusalem, A., \& Arias, A. (2020). Design of FDM 3D printed polymers: An experimental-modelling methodology for the prediction of mechanical properties. Materials \& Design, 188, 108414.

Gebisa, A. W., \& Lemu, H. G. (2019). Influence of 3D printing FDM process parameters on tensile property of ULTEM 9085. Procedia Manufacturing, 30, 331-338.

Gomez-Gras, G., Jerez-Mesa, R., Travieso-Rodriguez, J. A., \& Lluma-Fuentes, J. (2018). Fatigue performance of fused filament fabrication PLA specimens. Materials \& Design, 140, 278-285.

Guessasma, S., Belhabib, S., Nouri, H., \& Hassana, O. B. (2016). Anisotropic damage inferred to 3D printed polymers using fused deposition modelling and subject to severe compression. European Polymer Journal, 85, 324-340.

Justo, J., Távara, L., García-Guzmán, L., \& París, F. (2018). Characterization of $3 \mathrm{D}$ printed long fibre reinforced composites. Composite Structures, 185, 537-548.

Keshavamurthy, R., Tambrallimath, V., \& Saravanabavan, D. (2021). Development of Polymer Composites by Additive Manufacturing Process.

Kozior, T., \& Kundera, C. (2017). Evaluation of the influence of parameters of FDM technology on the selected mechanical properties of models. Procedia engineering, 192, 463-468. 
Lanzotti, A., Martorelli, M., Maietta, S., Gerbino, S., Penta, F., \& Gloria, A. (2019). A comparison between mechanical properties of specimens 3D printed with virgin and recycled PLA. Procedia Cirp, 79, 143-146.

Lee, C. S., Kim, S. G., Kim, H. J., \& Ahn, S. H. (2007). Measurement of anisotropic compressive strength of rapid prototyping parts. Journal of materials processing technology, 187, 627-630.

Lluch-Cerezo, J., Benavente, R., Meseguer, M. D., \& Gutiérrez, S. C. (2019). Study of samples geometry to analyze mechanical properties in Fused Deposition Modeling process (FDM). Procedia Manufacturing, 41, 890-897.

Martínez, J., Diéguez, J. L., Ares, E., Pereira, A., Hernández, P., \& Pérez, J. A. (2013). Comparative between FEM models for FDM parts and their approach to a real mechanical behaviour. Procedia Engineering, 63, 878-884.

Mirón, V., Ferrándiz, S., Juárez, D., \& Mengual, A. (2017). Manufacturing and characterization of 3D printer filament using tailoring materials. Procedia Manufacturing, 13, 888-894.

Mishra, S. B., Malik, R., \& Mahapatra, S. S. (2017). Effect of external perimeter on flexural strength of FDM build parts. Arabian Journal for Science and Engineering, 42(11), 4587-4595.

Mohamed, O. A., Masood, S. H., \& Bhowmik, J. L. (2017). Experimental investigation of timedependent mechanical properties of PC-ABS prototypes processed by FDM additive manufacturing process. Materials letters, 193, 58-62.

Nomani, J., Wilson, D., Paulino, M., \& Mohammed, M. I. (2020). Effect of layer thickness and cross-section geometry on the tensile and compression properties of 3D printed ABS. Materials Today Communications, 22, 100626.

Oviedo, A. M., Puente, A. H., Bernal, C., \& Pérez, E. (2020). Mechanical evaluation of polymeric filaments and their corresponding 3D printed samples. Polymer Testing, 106561.

Raney, K., Lani, E., \& Kalla, D. K. (2017). Experimental characterization of the tensile strength of ABS parts manufactured by fused deposition modeling process. Materials Today: Proceedings, 4(8), 7956-7961.

Salim, M. A., Termiti, Z. H., \& Saad, A. M. (2019). Mechanical properties on ABS/PLA materials for geospatial imaging printed product using 3D printer technology.

Singh, B., Kumar, R., \& Chohan, J. S. (2020). Polymer matrix composites in 3D printing: A state of art review. Materials Today: Proceedings.
Sood, A. K., Ohdar, R. K., \& Mahapatra, S. S. (2012). Experimental investigation and empirical modelling of FDM process for compressive strength improvement. Journal of Advanced Research, 3(1), 81-90.

Standard, A. S. T. M. (2015). D695, 2015, Standard Test Method for Compressive Properties of Rigid Plastics. ASTM International, West Conshohocken, PA.

Torre, R., Brischetto, S., Ferro, C. G., \& Maggiore, P. (2018). Characterization, in analogy with composites embedding unidirectional long fibres, of PLA specimens produced via FDM printing process. In Proceedings of the ICCS21 - International Conference on Composite Structures, September 4-7 2018, Bologna, Italy.

Türk, D. A., Brenni, F., Zogg, M., \& Meboldt, M. (2017). Mechanical characterization of 3D printed polymers for fiber reinforced polymers processing. Materials \& Design, 118, 256-265.

Vidakis, N., Petousis, M., Vairis, A., Savvakis, K., \& Maniadi, A. (2017). On the compressive behavior of an FDM Steward Platform part. Journal of computational design and engineering, 4(4), 339-346.

Wang, L., Gramlich, W. M., \& Gardner, D. J. (2017). Improving the impact strength of Poly (lactic acid)(PLA) in fused layer modeling (FLM). Polymer, 114, 242-248.

Wang, S., Ma, Y., Deng, Z., Zhang, S., \& Cai, J. (2020). Effects of fused deposition modeling process parameters on tensile, dynamic mechanical properties of 3D printed polylactic acid materials. Polymer Testing, 106483.

Wittbrodt, B., \& Pearce, J. M. (2015). The effects of PLA color on material properties of 3-D printed components. Additive Manufacturing, 8, 110-116.

Yadav, D. K., Srivastava, R., \& Dev, S. (2020). Design \& fabrication of ABS part by FDM for automobile application. Materials Today: Proceedings.

Yao, T., Ye, J., Deng, Z., Zhang, K., Ma, Y., \& Ouyang, H. (2020). Tensile failure strength and separation angle of FDM 3D printing PLA material: Experimental and theoretical analyses. Composites Part B: Engineering, 188, 107894.

Zhang, X., \& Wang, J. (2020). Controllable interfacial adhesion behaviors of polymer-on-polymer surfaces during fused deposition modeling $3 \mathrm{D}$ printing process. Chemical Physics Letters, 739, 136959.

Zhao, Y., Zhao, K., Li, Y., \& Chen, F. (2020). Mechanical characterization of biocompatible PEEK by FDM. Journal of Manufacturing Processes, 56, 28-42. 